\title{
A Decentralized Multi Agent ANN Based Control Technique for Operation Cost Optimization of Isolated Microgrid Systems
}

\author{
Asad Ullah ${ }^{1 \mathrm{a}}$, Salman Amin ${ }^{\text {bb }}$, Shaikh Saaqib Haroon ${ }^{1 \mathrm{c}}$, Intisar Ali Sajjad ${ }^{1 \mathrm{~d}}$, \\ Hammad Shaukat ${ }^{1 \mathrm{e}}$
}

RECEIVED ON 17.06.2019, ACCEPTED ON 03.03.2020

\begin{abstract}
With an ever increasing electrical load demand and the associated fuel price to generate it, researchers are compelled to find alternate, cheap and environment friendly ways for power generation to cater to this technoeconomic conundrum. Renewable Energy Sources (RES) are now being integrated in Distributed Generation (DG) based environment as a solution to this problem, hence resulting in Microgrids, with multiple sources and loads demarcating their footprint. Control and management of a diverse generation profile within a single microgrid is arduous and computationally intensive for a single centralized controller. This paper addresses this inherent problem and proposes a decentralized Multiagent based intelligent control technique to efficiently encompass the heterogeneous generation profile of Microgrids. Artificial Neural Network (ANN) based intelligent agents are deployed at the planning stage for each component of the Microgrid. These agents are responsible for maintaining individual local control parameters within the prescribed control margins, hence creating a multi-agent environment in a Microgrid structure. The proposed intelligent multi-agent control scheme is tested on a test system to furnish its merits over its traditionally employed counterparts. Simulation results show that ANN integration not only reduced the computational burden but also reduced the overall operating cost (around $10.2 \%$ ) by reducing the thermal generation.
\end{abstract}

Keywords: ANN based Multi Agent Management, Cost Optimization, Decentralized Microgrid Control and Management, Renewables in Isolated Microgrid

\section{INTRODUCTION}

I $\mathrm{n}$ the last half century, major improvements have been made in electric grid, transmission and distribution network with an ever-increasing electrical load demand. Sophisticated and reliable electrical network brought ease in lives and ultimately became a part of every field of life. With the growth of electrical system, the challenges of system reliability, maintaining power quality and minimizing, transmission losses have become serious concerns. To cater some of these issues Distributed Generation
(DG) based environment was introduced to supply local load independent of main grid. This kind of DG environment is called Microgrid.

According to US department of energy [1], Microgrid is a combination of different power sources and loads at a common place to meet the load demand within or outside the energy market. It is a DG based environment in which load demands, power quality and power losses are dealt locally. Integration of control and communication network for all sources and loads is essential part of any Microgrid and is a complex problem [2-5].

\footnotetext{
${ }^{1}$ Department of Electrical Engineering, University of Engineering and Technology, Taxila, Pakistan.

Email: aasadullah428@hotmail.com (Corresponding Author), bsalman.amin@uettaxila.edu.pk

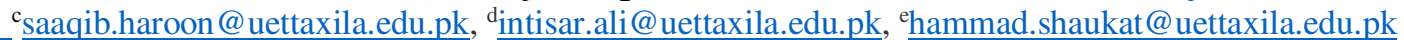

This is an open access article published by Mehran University of Engineering and Technology, Jamshoro under CC BY 4.0 International License. 
Introduction of power electronic control units have made this microgrid environment user friendly in terms of meeting the customers' demand and utility constraints. In Microgrid, utility wants maximization of profit by meeting the load demand, minimizing losses and better efficiency, while consumer desires power quality and reliability to be maintained $[6,7]$. These distributed generation units are responsible for providing power to local load and excess power to the main grid or storage units. To increase reliability of Microgrids, storage units have also been integrated with control units.

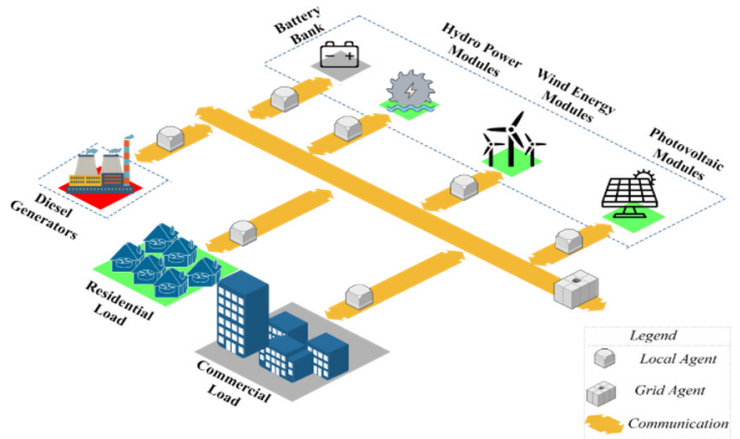

Fig. 1: Block Diagram of a typical microgrid environment

Whether it is the central or Microgrid, ever increasing prices of fuel force to focus the power system operators on renewable energy resources. Involvement of renewable energy sources in distributed generation network has been increased very much in last two decades. Solar, wind and micro hydel turbines are being used as clean alternate energy sources. Integration of renewables into central or Microgrids has shaped a new environment of power system which has an additional advantage of minimum usage of fossil fuels. Renewable resources based distributed generation is intermittent and excess power can be stored for later use to minimize the use of conventional thermal generation.

Control and management of Microgrids is serious concern in adaptation of Microgrid environment with distributed generations due to diverse nature of renewables. Several techniques have been proposed, studied and implemented over last few decades. Microgrids can be isolated or grid connected. A typical microgrid environment is shown in Fig. 1. Microgrids having centralized control and energy management involve complex communication and computational burden on single controller. This situation is even more complicated by addition of renewables, storage devices and plug and play electric vehicles.

Decentralized control was introduced $[8,9]$ to reduce complexities and computational burden on single controller to make decisions efficiently in real-time environment. Each local controller is responsible for intelligent control and management of specific unit. All local controllers then take part to design a network (microgrid environment). Intelligence at local level is more easily configurable, adaptable and flexible for addition of new elements. Even some researchers define the Microgrid as the one having mandatory intelligence in control unit.

Microgrid structure and component is wide field of research. Microgrid contains distributed electric power sources, load units and storage elements. Microgrid is 'safe heaven' for integration of DG units, energy storage and management and control units according to consumer and retailer requirements and benefits. Distributed sources may be conventional or non-conventional power sources satisfying local load demand as primary objective.

Integration of artificial intelligence techniques convert traditional grid into smart-grid. They mimic the human analysis, judgment, and decision by modelling human intelligence in situation identification, assessment and implementation. Electric load forecasting has proven to be a non-linear and complex problem. For optimal planning and operation of DG based complex systems, modern system theory and optimization techniques are being applied for operational cost reduction [10]. Microgrids are more intelligent and reliable because of advance infrastructure and integrated intelligent operation and planning technologies. Prediction of electric load and intermittent nature of sources plays vital role in planning and optimization of Microgrid because it provides a balance between generation and demand, to optimize the generation cost [11]. Authors in [12] also proposed optimization of load and cost with Short Term Load Forecasting (STLF) for small homes based Microgrids. [13] presented similar optimization technique for load in microgrid with 
renewable integration and local case study. Currently, the most widely used methods are based on artificial neural networks (ANNs) since 1980s. ANNs are one of the most popular options due to their ability to automatically learn from experience and adapt accordingly to give generalized results, like human brain. It has flexibility to adapt the open, varying and incomplete information environment. Compared with traditional algorithms, ANN can perform with timevarying, and nonlinear systems. For example, unlike statistical model-based load forecasting techniques, ANNs can handle non-linearity and dynamic data. Due to handling capability of non-linearity, well-modelled neural networks have proven to be suitable for load forecasting and planning in Microgrid. ANNs have strong ability for data analysis that can be used to process data and automatically extract the relationship between incoming and existing data [14, 15]. Load data in Microgrid is dynamic because real time electric load is seasonal, periodic and influenced by various variables and their complex combinations $[16,17]$. For example, the load curve will be different on weekdays and weekends and according to weather conditions load can be different for same hour of same day compared to last week. So, ANN based modelling can handle such non-linearity for load prediction.

A workshop organized by The National Science Foundation, demonstrated that ANN can be successfully used in STLF with reasonable accuracy [18]. ANN mainly emphases on data mining to develop model of system for pattern recognition to forecast according to that model. ANN based models for STLF are not unique and once defined, need not to be updated frequently [19]. But the ANN structure modelling requires careful handling of variables that can affect the output. A well modeled neural network can handle non-linear data even when there is no relationship between the current data and modeled data. For STLF in Microgrid of a particular hour in specific day of year the best combination of the variables includes the previous load data, weather conditions at that time, consumers' energy usage patterns and calendar type. This grid data then used for prediction of future load consumption, improving the planning in Microgrid [20 - 22]. Energy management system presented in this paper for Microgrid, makes decision according to ANN based forecasting of future load consumption which allow it to optimize power from DGs effectively, hence reducing the operational cost $[23,24]$.

\section{DECENTRALIZED CONTROL OF MICROGRID}

Decentralized system of control and management at Microgrid level provides the easy solution to handle multiple sources with less computation and communication burdens on single controller.

In decentralized control environment each element in the Microgrid network acts as decision maker, locally. It means that every element makes decision according to its own constraints and requirements. Finally, the subsequent behaviour of system is the accumulated response of all individual responses. Every element is controlled by its controller at local level irrespective of the decisions other units are making [25]. All the elements then act in synergy to achieve common goal.

General pseudocode flow algorithm for agent based decentralized control of RES integrated Microgrid is shown in

Fig 2. Electric load demand is processed by local load agent and the information is passed on to individual RES agents. As the goal is to meet the load demand with minimal usage of thermal generation, RES based agents try to achieve load demand. The demand greater than RES generation is dealt by battery storage and/or thermal generation. Internal layered architecture and working of individual agent is explained in next section.

\section{MULTI AGENT SYSTEMS}

From past few decades, intelligence in decentralized control units is topic of research in many fields of life including medical, transportation, mobile communication and robotics.

Main objective in decentralized control is to design a local controller to automate the process independently and intelligently for an element (an independent part of a system). Such a local controller is called Agent. 


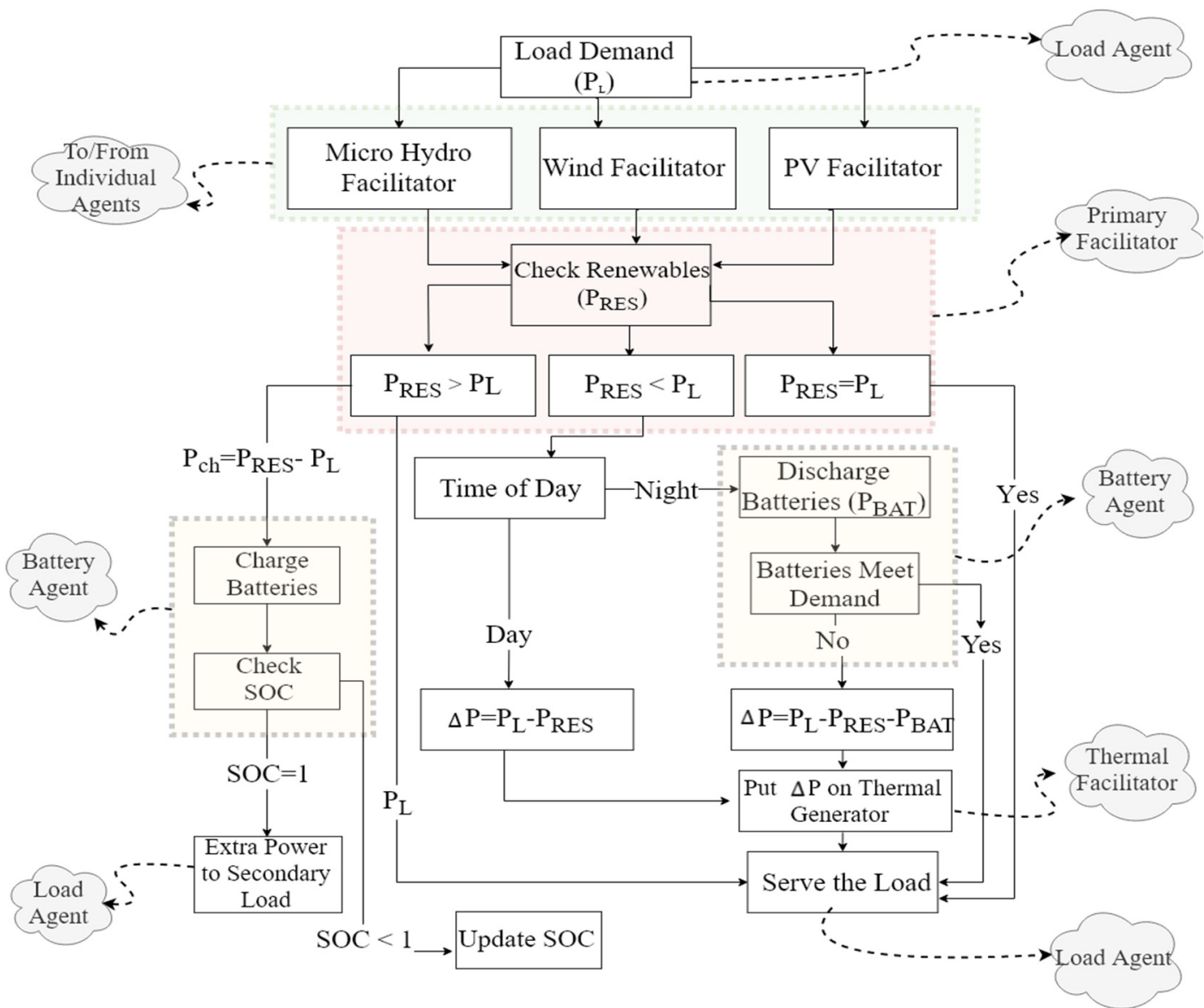

Fig 2: Proposed algorithm for decentralized control (The balloons represent the software block where the corresponding decision is taken)

Agents of different elements in Microgrid coordinate together to form multi agent based decentralized control.

Integration of different agents, while each working independently with its associated element, is to take decisions meeting the local constraints efficiently and rapidly [26]. Artificial Intelligence (AI) has been developing since 1980s with ability of handling problems according to built-in knowledge and learning [27, 28]. Some AI based systems (ARCHON; for example [29]) is designed to act in real time environment. These kind of systems are a collection of single agent AI systems which result in multi-agent based AI system suitable to perform in real-time environment [26].

So, an agent is an object which controls an environment by sensing the change using sensors and sending appropriate signals to actuators. Like in human motions, if we consider senses and actions as agents and body as a decentralized Multi Agent system (MAS). A robot is also an example of decentralized multi agent system which has sensors and actuators as different local agents, all integrated to perform a task. Similarly a software agent has sensors which takes input from the environment and issues the commands to actuators to perform an action in an [30]. But, the story is not such simple and in practical sense, main challenge is to make right decision at right time. Agent in a network introduce intelligence in decision and planning. Agents may not learn from the environment completely. It takes input from environment and rest of the calculation needs to be done with common reasoning [31]. A software agent is a program to monitor, control and act according to situation and when equipped with artificial intelligence, it can best serve its purpose. A simple block diagram of architecture of a software agent is shown in Fig. 3: 


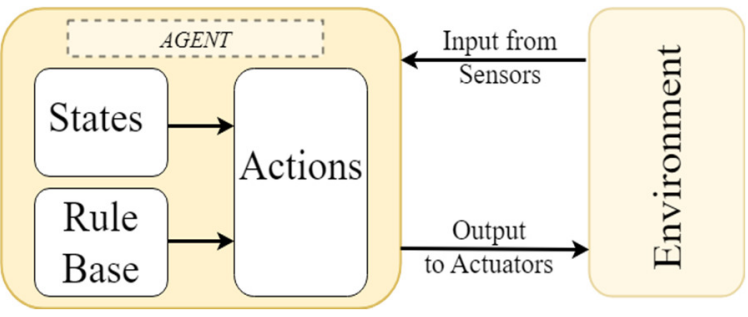

Fig. 3: Basic architecture of a software agent

Detailed architecture of a typical software agent showing individual layers is shown in Fig. 4.

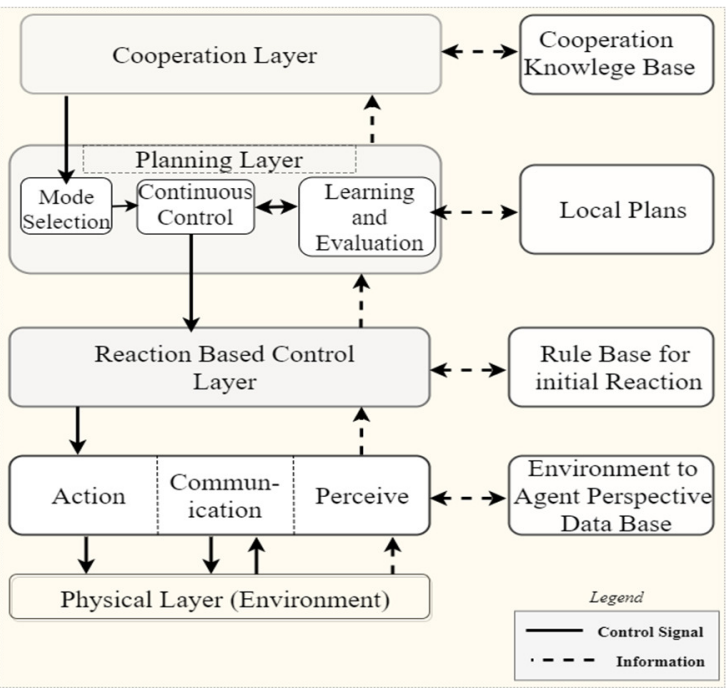

Fig. 4: Layered architecture of a software agent

\section{MODELLING OF COMPONENTS IN A MICROGRID}

A Microgrid is complex arrangement of different components which may include diesel generator, photovoltaic system, wind generation system, micro hydro turbines and energy storage devices. Microgrid having centralized control would have a single agent controlling the parameters (i.e. input/output power, power flow, cost and other constraints). Decentralized control with each component having its own local control agent, has proven its advantage over centralized control. In following subsections modelling of individual components of a typical Microgrid is presented first. Then combined control of components in a decentralized multi agent architecture is presented deploying ANN intelligence. The proposed controller is then applied to a real life Microgrid environment of a resort island.

\subsection{Modeling of Diesel Generator:}

Governor and thermal engine is modeled into one transfer function which takes input of required speed and current speed of generator and the output is mechanical speed, which is input of synchronous generator. Transfer function as the model of control unit for this is given in equation (1) [32-33]:

$H_{c}=\frac{k\left(1+T_{1} s\right)}{1+T_{s} s+T_{1} T_{2} s^{2}}$

Actuator is modeled in transfer function as:

$\mathrm{H}_{\mathrm{a}}=\frac{1+\mathrm{T}_{4} \mathrm{~s}}{\mathrm{~s}\left(1+\mathrm{T}_{5} \mathrm{~s}\right)\left(1+\mathrm{T}_{6} \mathrm{~s}\right)}$

where $\mathrm{k}$ is proportionality gain and $\mathrm{T}_{\mathrm{i}}(\mathrm{i}=1,2,3 \ldots 6)$ are time constants.

\subsection{Excitation System Modeling:}

The excitation system of generator is modeled as [32, 33]:

$\frac{\mathrm{V}_{\mathrm{fd}}}{\mathrm{V}_{\mathrm{ro}}}=\mathrm{H}_{\mathrm{ex}}=\frac{1}{\mathrm{~K}_{\mathrm{s}}+\mathrm{sT}_{\mathrm{e}}}$

where $V_{f d}$ is excitation voltage (output of the unit) and $V_{\text {ro }}$ is regulator output (input of excitation system). $K_{s}$ and $\mathrm{T}_{\mathrm{e}}$ are gain and time constant, respectively.

\subsection{Modeling of Photovoltaic System:}

Photovoltaic (PV) unit consist of three components: PV cell, PV arrays and PV module. Cells in series combination is PV module. Multiple modules in series and parallel combination forms a PV system. In this study PV system is modeled according to factors governing the PV output power. These factors include input to the solar cell (solar irradiance), size of PV system and efficiency of modules $(\eta)$ and is given by:

$\eta=\eta_{m} \eta_{p c} P_{f}$

where, $\eta_{m}$ is module efficiency, $\eta_{p c}$ is efficiency according to power output. $\mathrm{P}_{\mathrm{f}}$ is packing factor. $\eta_{\mathrm{m}}$ is given by formula [34]:

$\eta_{\mathrm{m}}=\eta_{\mathrm{r}}\left[1-\beta\left(\mathrm{T}_{\mathrm{c}}-\mathrm{T}_{\mathrm{r}}\right)\right]$ 
Here, $\eta_{\mathrm{r}}$ is module reference efficiency. $\beta$ is temperature coefficient. $T_{r}$ is reference temperature of $\mathrm{PV}$ single module at which efficiency is $\eta_{r}$ and $T_{c}$ is temperature of PV cell.

Direct normal and diffused radiations from the sun is measured using different instruments (pyrheliometer and pyranometer, respectively). Total irradiance (in $\frac{\mathrm{W}}{\mathrm{m}^{2}}$ ) for PV system is then calculated by using following formula:

$G_{t}=G_{b} R_{b}+G_{d} R_{d}+\left(G_{b}+G_{d}\right) R_{r}$

where, $G_{t}$ is total irradiance and $G_{b}$ and $G_{d}$ are solar irradiance of direct normal and solar irradiance of diffused radiation respectively. While $R_{d}$ and $R_{r}$ are tilt factors of direct and reflected radiation, respectively [35].

So, if solar modules are over the area of $\mathrm{A}_{\mathrm{PV}}$ in $\mathrm{m}^{2}$, final equation for typical monocrystalline PV module output can be written as [36]:

$\mathrm{P}_{\mathrm{PV}}=\mathrm{G}_{\mathrm{t}} \mathrm{A}_{\mathrm{PV}} \eta$

$\mathrm{P}_{\mathrm{PV}}$ is output of whole PV system in watts.

\subsection{Modeling of Wind Energy System:}

Wind energy system consists of wind turbine, mechanical shaft, gear box, electric generator, brake system and tail. Wind velocity is input of the turbine and rotates the turbine. Mechanical shaft is attached with turbine which runs the gear box. An electrical machine is attached with gear box.

Electrical output depends on the aerodynamics of turbine, wind distribution curve and height from the ground. Wind turbine electrical output at specific wind speed with hub height can be defined by power law equation [37]:

$\mathrm{V}_{\mathrm{z}}=\mathrm{V}_{\mathrm{i}}\left[\frac{\mathrm{z}}{\mathrm{z}_{\mathrm{i}}}\right]^{\mathrm{x}}$

here $V_{z}$ is wind speed at the hub of the turbine and $V_{i}$ is the wind speed at reference height $z_{i}$ and $z$ is height of hub. $\mathrm{x}$ is exponent of power law equation.
Normally, for wind turbines velocities of wind are characterized and at specific wind range, action of turbine is included in modelling of it. There is nominal velocity $\left(\mathrm{v}_{\text {nom }}\right)$, at which turbine gives rated power output $\left(\mathrm{P}_{\text {nom }}\right)$ and works fine. There is threshold of maximum velocity ( $v_{c o}$ - cut out velocity) above which turbine is too dangerous to operate mechanically so they are stopped. Below nominal velocities $\left(\mathrm{v}_{\mathrm{ci}^{-}}\right.$cut in velocity), turbines do not act in linear behavior, so this behavior is also included in model.

Simplified model is provided below [38-39]:

$\mathrm{P}_{\mathrm{wd}}=\left\{\begin{array}{cc}0, & \mathrm{v}<\mathrm{v}_{\mathrm{ci}} \\ \mathrm{aV}^{3}-\mathrm{bP}_{\mathrm{nom},}, & \mathrm{v}_{\mathrm{ci}}<\mathrm{v}<\mathrm{v}_{\text {nom }} \\ \mathrm{P}_{\text {nom }}, & \mathrm{v}_{\text {nom }}<\mathrm{v}<\mathrm{v}_{\mathrm{co}} \\ 0, & \mathrm{v}>\mathrm{v}_{\mathrm{co}}\end{array}\right.$

where, $\boldsymbol{P}_{\boldsymbol{w} \boldsymbol{d}}$ is wind output power in $\frac{\boldsymbol{k} \boldsymbol{W}}{\boldsymbol{m}^{\mathbf{2}}}$ and

$\boldsymbol{a}=\frac{P_{\text {nom }}}{v_{\text {nom }}^{3}-v_{c i}^{3}}, \quad \boldsymbol{b}=\frac{v_{c i}^{3}}{v_{\text {nom }}^{3}-v_{c i}^{3}}$

So, total power output from the wind turbine is given by:

$\mathrm{P}_{\mathrm{w}}=\mathrm{P}_{\mathrm{wd}} \times \mathrm{A}_{\mathrm{w}} \times \eta_{\mathrm{w}}$

where, $A_{w}$ is the wind total sept area and $\eta_{w}$ is the overall wind turbine efficiency. $\mathrm{P}_{\text {nom }}$ here is nominal power with swept area so final equation will be:

$\mathrm{P}_{\mathrm{w}}=\mathrm{P}_{\mathrm{wd}} \times \eta_{\mathrm{w}}$

\subsection{Modeling of Micro Hydel Plant:}

Run of river micro hydel power plants are integrated in Microgrid under study. Electric power output is proportional to: water density, flow of river (stream flow), height of head of reservoir and gravity acceleration constant. The simplified model is given below [40, 41]:

$P_{h}=\rho \times Q \times H \times g \times \eta_{h}$

where, $\mathrm{P}_{\mathrm{h}}$ is output power of hydro power plant in watts $(W) . \eta_{h}$ is overall efficiency of hydro power plant. $g$ is gravitational acceleration $\left(9.8 \mathrm{~m} / \mathrm{s}^{2}\right)$.

$$
\begin{aligned}
& \rho=\text { water density }=1000 \frac{\mathrm{kg}}{\mathrm{m}^{3}} \\
& Q=\text { stream flow }\left(\frac{\mathrm{m}^{3}}{\mathrm{~s}}\right)
\end{aligned}
$$


$\mathrm{H}=$ head height $(\mathrm{m})$

\subsection{Modeling of Battery Storage:}

Batteries are modelled according to State of Charge (SOC), Depth of Discharge (DOD), battery capacity and type of battery. SOC of battery is calculated in percentage of charge available. A fully charged battery is said to have 100 percent SOC and fully discharged battery has zero percent SOC. For batter efficiency and longer battery life, batteries are never discharged to zero SOC and are kept charged at 100 percent whenever possible.

This study uses an energy storage device model based on lead acid batteries. In order of achieve maximum efficiency and life from a lead acid battery, the charging and discharging rates must be limited around $\mathrm{C} / 10$. Where $\mathrm{C}$ is the total capacity of the battery when at $100 \%$ SOC. Charging and discharging of batteries are modeled as follow $[42,43]$ :

$\operatorname{SOC}(\mathrm{t}+1)=\operatorname{SOC}(\mathrm{t})(1-\sigma(\mathrm{t}))+\left[\mathrm{I}_{\text {bat }} \times \Delta \mathrm{t} \times \frac{\eta_{\mathrm{c}}(\mathrm{t})}{\mathrm{C}_{\mathrm{bat}}}\right]$

where, $\sigma(\mathrm{t})$ is self-discharge rate at time span $t$ and mostly taken as $0.02 \%$ of battery capacity [44]. $\mathrm{C}_{\text {bat }}$ is total battery capacity in Ah. $\mathrm{I}_{\text {bat }}$ is current from or to the battery. $\eta_{c}$ is charging efficiency of the battery and charging unit, combined. Similarly, discharging of batteries can be modelled as:

$\operatorname{SOC}(t+1)=\operatorname{SOC}(t)(1-\sigma(t))-\frac{I_{\text {bat }} \times \Delta t}{\eta_{\text {dis }} \eta_{\text {inv }} \times C_{\text {bat }}}(12)$

$\eta_{\text {dis }}$ is discharging efficiency and $\eta_{i n v}$ is inverter efficiency. For discharging battery current $\mathrm{I}_{\text {bat }}$ can be calculated as the remaining current after renewables fed load and rest of load demand current is battery discharge current; as:

$I_{\text {bat }}=\frac{P_{\text {demand }}(t)}{\eta_{\text {in }}(t) V}-\frac{P_{\text {renew }}}{V}$

If the $\mathrm{I}_{\text {bat }}$ is positive, current is discharging current and negative $\mathrm{I}_{\mathrm{bat}}$ indicates charging current available to batteries.

\subsection{Secondary Load:}

The secondary load (dump load) is designed to absorb the excess power from RES with the condition that the battery storage is fully charged. Whole unit contains series connected eight sets of resistors. Up to $446.25 \mathrm{~kW}$ of excess power can be dumped with $1.75 \mathrm{~kW}$ of step and binary progression which is managed by secondary load agent.

\section{ROLES OF LOCAL AGENTS, FACILITATORS AND PRIMARY FACILITATORS}

In multi agent based intelligent control and management of Microgrid, the information flows from bottom to top layer and control signal comes from top to bottom layers. Each agent will take care of local constraints to control, manage and optimize its component. It will provide a flag indicating its status (available or not) and an additional flag of power flow direction (inward or outward) in case of energy storage system. Decision of each agent take part in global optimization (minimizing the cost and emissions of thermal units and reducing communication burden and hence associated delay). Additionally, in planning layer of multi agent system at colony layer for global optimization, learning from previous situations has been introduced in this work.

Generally, multi agent system is used in computer science field to reduce communication burden and computation time. For decentralization of control system of Microgrid, multi agent system was modified to work in Microgrid environment. Architecture of an agent was designed and modelled according to InteRRap layered model [45].

The modified InteRRap architecture is modelled in two stages. First stage is taking input from the environment using sensors, perceive the information, identify the situation, plan according to data base set of rules and generate control signal. Next stage is learning of agent for different situations and improving decision ability and reducing computation time to work better in real time scenarios. The agents were modeled in MATLAB so that they can be connected easily with each other to form a Microgrid environment.

There are four modes for each generation source: 
Active, hot standby, cold standby and inactive. Active mode is when the source is giving power. In hot standby, generation is ready, but source is not sharing power. In cold standby a source maybe temporarily shut down due to any infeasible circumstances (e.g. wind turbine in case of high velocity wind). In inactive mode, system is permanently shut down and will not take part in Microgrid. A brief introduction of primary facilitator, agents and facilitator associated with each component is given in following subsections:

\subsection{Primary Facilitator and Individual Facilitators}

Each type of source described in next section will have multiple local agents. Anyone of these local agents which has highest generation available at a certain time acts as facilitator. This facilitator then gets the information from all agents and is responsible for communication with primary facilitator. Fig. 5 shows the layout of sources, agents facilitators and primary facilitator in multi agent based Microgrid.

Grid agent acts as primary facilitator which is responsible for global optimization of whole system. It shares the information with all facilitators and ultimately, local agents are communicated, and they act accordingly to take part in global optimization.

\subsection{Local Agents of Different Components:}

\subsubsection{Photovoltaic Agent (PVA):}

As total solar generation is from multiple arrays each having its local agent. Each PV agent in Microgrid is responsible for monitoring the environment (solar irradiance in this case) and observing output from the respective solar array.

\subsubsection{Wind Agent (WA):}

Each wind turbine has its own agent and takes input from the environment through sensors and perceive the raw information, so the mathematical model of wind can perform computations.

\subsubsection{Hydropower Plant Agent (HPA):}

Hydropower power plant agents takes stream flow data as input and monitors the output from the hydro plant and represent the plant in the environment.

\subsubsection{Thermal Agents (TA):}

Each of individual thermal agent take the information from environment and are responsible for monitoring the output power associated with their generator. Mode of generation is also monitored and implemented by these agents in planning layer. Mode selection is shown in Fig. 66:

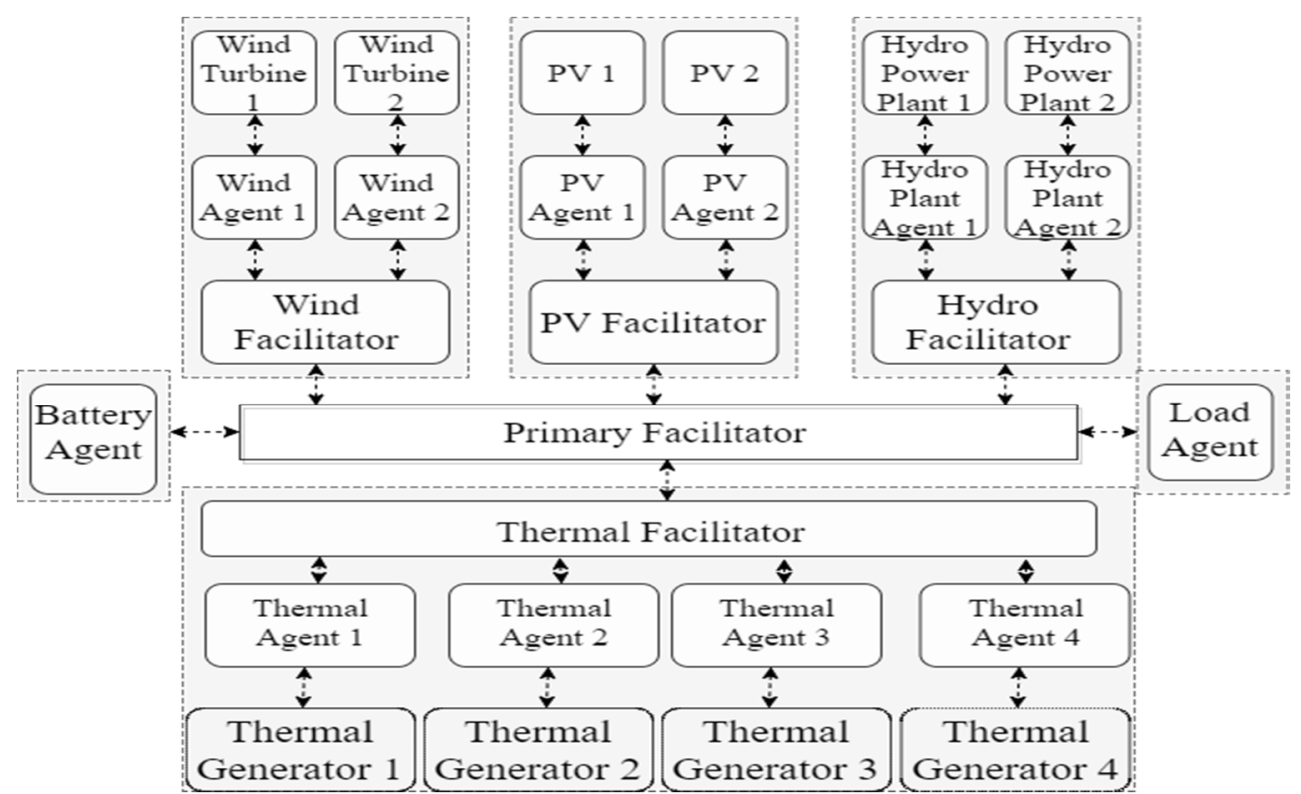

Fig. 5: Facilitators associated with agents 


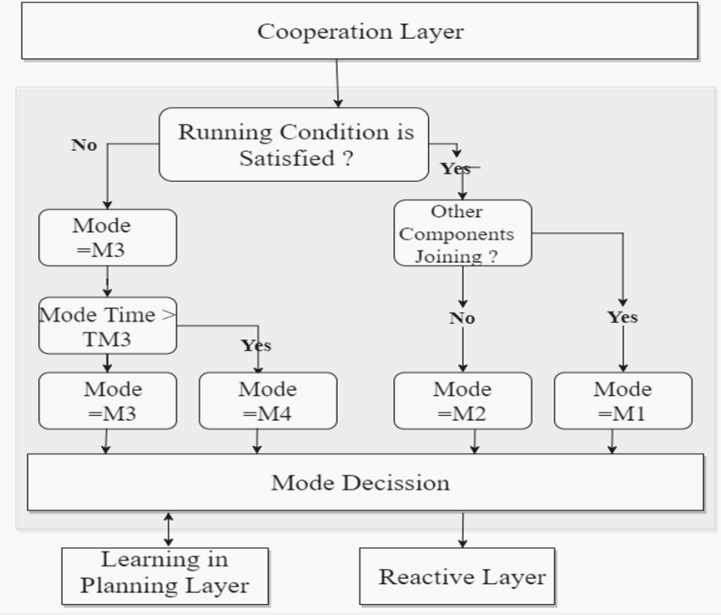

Fig. 6: Mode selection in planning layer

In planning layer of thermal agent, each thermal unit is characterized and prioritized according to cost of each generator. It takes input and calculates power demand difference. Then it is solved by considering it as economic dispatch problem. The constraints and base rules are as follow:

$$
\begin{aligned}
& P_{d} \\
& =
\end{aligned} \mid \begin{array}{ll}
0, & \Delta P \leq 0 \\
P_{d 1}, & 0<\Delta P<P_{d 1_{\text {max }}} \\
P_{d 1}+P_{d 2} & P_{d 1_{\text {max }}}<\Delta P<P_{d 1_{\text {max }}}+ \\
& P_{d 2_{\text {max }}} \\
P_{d 1}+P_{d 2}+ & P_{d 1_{\text {max }}}+P_{d 2_{\text {max }}}<\Delta P< \\
P_{d 3} & P_{d 1_{\text {max }}}+P_{d 2_{\text {max }}}+P_{d 3_{\text {max }}} \\
P_{d 1}+P_{d 2}+ & \Delta P>P_{d 1_{\text {max }}}+P_{d 2_{\text {max }}}+ \\
P_{d 3}+P_{d 4} & P_{d 3_{\text {max }}}
\end{array}
$$

$P_{d}$ is total power by the thermal generation. $P_{d i}$ is power by $\mathrm{i}^{\text {th }}$ thermal generator and $\mathrm{P}_{\mathrm{di}_{\max }}$ is maximum power rating of $i^{\text {th }}$ thermal generator.

$\Delta \mathrm{P}=\mathrm{P}_{\text {demand }}-\mathrm{P}_{\text {renewable }}$

Positive $\Delta P$ means that renewable power is less than the power demand. So, there is need of thermal generator. Thermal generation agent also takes input from the battery agent. Management in colony layer is carried out in such way that load demand is met by renewables then batteries and then thermal if load demand is still higher or duration is longer.

One of the thermal generator has capacity to take whole load, as a backup generator. Rest of three thermal generators have their own costs of running so, load is assigned to generator having lowest price per $\mathrm{kWh}$. Thermal facilitator is responsible to provide the deficient power in system after all other sources have been utilized to their full available limits. So, thermal facilitator takes input from all other facilitators.

\subsubsection{Battery Agent (BA):}

Battery agent supervises charging and discharging according to SOC of batteries. The battery agent makes sure that batteries are only charged when there is excess of renewables after load demand is meet. Batteries are not charged at thermal generation. Lead acid batteries are designed to charge and discharge at maximum rate of $\frac{C_{b a t}}{10}$. BA also ensures that batteries are not charged and discharged at a rate given by following equation (equation 14):

$$
\mathrm{P}_{\mathrm{ch}}, \mathrm{P}_{\mathrm{dis}}=\frac{0.1 \times \mathrm{V}_{\mathrm{bat}} \times \mathrm{Q}_{\mathrm{bat}}}{\Delta \mathrm{t}}
$$

Similarly, the BA is also responsible for keeping the SOC of batteries within following limits.

$20 \%<\mathrm{SOC}_{\text {bat }}<100 \%$

Through a flag indicator, this agent also indicates whether batteries are ready to give the power $\left(\mathrm{P}_{\mathrm{ij}}\right)$ or not. Another flag indicator of this agent shows that either battery needs charging or not.

\subsubsection{Load Agent (LA):}

By checking the flag indicators $\left(\mathrm{a}_{\mathrm{ij}}\right)$ and respective powers $\left(\mathrm{P}_{\mathrm{ij}}\right)$ from all other agents, the load agent constantly supervises the load demand in real time and checks if load demand is met. If load demand is greater than generation and specific generator can give power, it requests to run that generator to meet the load demand. If all generations are working and still need of more power, non-critical loads will be shut down according to priority list. 


\subsubsection{Secondary Load Agent}

If there is excess power from renewable generation the load and batteries are also fully charged, this power need to be dumped. Alongside the load agent, a secondary load agent is present. This agent, when receives the flag from the load agent, the excess power is diverted towards the secondary load (dump load).

\subsubsection{Grid Agent (GA):}

Grid agent is there to monitor the power flows in Microgrid. In case of overloading of distribution network, it raises a flag which indicates the overloading and sends message to load agent to reduce load. It also senses fault in Microgrid and requests respective facilitator to clear that fault whenever possible.

\section{GLOBAL OPTIMIZATION IN MICROGRID}

At colony level of Microgrid, management system is designed to maximize the system benefits as whole. As discussed in earlier section, objective is to minimize the cost of overall operation. To achieve this objective thermal generation must be used at minimum while utilizing renewable sources at maximum possible limits. So, generalized optimization problem can be modeled as:

$\operatorname{minf}=\sum_{\mathbf{i}=\mathbf{1}}^{\mathrm{T}} \sum_{\mathbf{j}=\mathbf{1}}^{\mathbf{N}_{\mathrm{g}}} \mathbf{a}_{\mathrm{ij}} \mathbf{P}_{\mathrm{ij}} \mathbf{C}_{\mathrm{ij}}$

subject to:

$\sum_{\mathrm{i}=\mathbf{1}}^{\mathbf{T}} \sum_{\mathbf{j}=\mathbf{1}}^{\mathbf{N}_{\mathrm{g}}} \mathbf{a}_{\mathrm{ij}} \mathbf{P}_{\mathrm{ij}} \mathbf{C}_{\mathrm{ij}}=\mathbf{P}_{\text {load }}+\mathbf{P}_{\text {loss }}$

This equation requires parameters from each agent for $\mathrm{j}^{\text {th }}$ generator at $\mathrm{i}^{\text {th }}$ time of day. The $\mathrm{a}_{\mathrm{ij}}$ value is referred as flag here and processed by individual agent and have binary output ( 0 or 1$)$. It specifies whether the specific agent at $\mathrm{i}^{\text {th }}$ time is ready to provide power $\mathrm{P}_{\mathrm{ij}}$ to the system or not. $C_{i j}$ is the unit cost of $j^{\text {th }}$ generator at $\mathrm{i}^{\text {th }}$ time to generate power. $\mathrm{P}_{\mathrm{ij}}$ is amount of power that $\mathrm{j}^{\text {th }}$ generator at $\mathrm{i}^{\text {th }}$ time is providing. Hence, the term $\mathrm{a}_{\mathrm{ij}} \mathrm{P}_{\mathrm{ij}} \mathrm{C}_{\mathrm{ij}}$ gives the cost of specific generator at specific time (if $\mathrm{a}_{\mathrm{ij}}$ is zero, term will be zero). So, the objective function is to minimize the cost of all the generators subject to the constraint that total generation should be equal to demand $\mathrm{P}_{\text {load }}$ plus all the losses of the system $\mathrm{P}_{\text {loss }}$. $\mathrm{P}_{\text {loss }}$ is defined here as the difference of power generation and total power demand, i.e. $\mathrm{P}_{\text {loss }}=($ total generaion $)-\mathrm{P}_{\text {load}}$.

This objective function is incorporated in multi agent based colony layer. Alongside optimization with intelligent multi agent technique, some of the features are also added which improve the effectiveness of intelligent agents. Real time management and planning of generators, storage and load units is introduced in local planning layers of local agents and at Microgrid level.

\section{ARTIFICIAL NEURAL NETWORK BASED PLANNING}

ANN is a nature inspired algorithm. It does not need linguistic model and expert knowledge in linguistic terms. This method acts as black box modelling of multivariable, nonlinear and dynamic systems. By simple training using available data, observer can be modeled. As human brain can perform complicated work and learn from the previous experience and next time learning and action is also based on learnt data. Neural network mimics this property of human brain to solve complex problems, predict classification and recognize pattern of coming data before it happens. Commonly ANN comprise of multiple layers of neurons (basic building block). These neurons are interconnected in a network and each neuron has weighted input to tune it according to model under consideration.

ANN based learning is introduced in this work for handling situations that are not predefined in data base of agent. This will not only allow to handle situation, but these situations are added in learning process for future modeling of load.

\subsection{Artificial Neurons}

Artificial neurons are mathematical model of human neurons. Every input to single neuron is connected through a weight. All these weighted inputs are added and passed to nonlinear function known as activation function which gets inputs from neurons. Fig. 7 shows this schematically. Mathematically, it is expressed as given in equation (16): 
$\mathrm{z}=\sum_{\mathrm{i}=1}^{\mathrm{p}} \mathrm{w}_{\mathrm{i}} \mathrm{x}_{\mathrm{i}}=\mathrm{w}^{\mathrm{T}} \mathrm{x}$

According to situation of model activation function can be sigmoidal, parabolic or hard binary of zero and one (limiter). For example: $\sigma(z)=\left\{\begin{array}{ll}0, & z<0 \\ 1, & z \geq 0\end{array}\right.$ is hard limit linear activation function while, $\sigma(z)=$ $\frac{1}{1+\exp (-s z)}$ is sigmoidal activation function. Due to non-linear and time varying nature of the data, sigmoidal activation function is chosen for load forecasting [46].

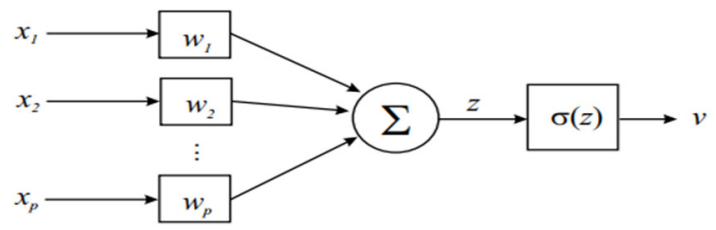

Fig. 7: Single neuron with weights and activation function

\subsection{Architecture of Neural Network}

Neurons in ANNs are placed in layers to form neural network. There may be single or multiple layers of neurons and network depending upon the complexity of system model and amount of precision required.

\subsection{Learning in ANNs}

In this research work, we have used ANN toolbox of MATLAB. It takes input data for training and according to that data, neural network tunes the weights of neurons by Levenberg-Marquardt iterative optimization technique. When weights are tuned, it predicts a similar model and according to specific input to the network, it can forecast the output of the system under study. Based on the predicted model, ANN takes part planning and decisions. After that decision is made, predicted model is updated in data base of planning layer. We use it to forecast the load of every next hour so that thermal generators can be started and shut down to reduce hot standby cost.

ANN models and predicts by taking into consideration the multiple decision variables. These variables are, load at the same hour in previous day and average load of previous day, load at same hour in previous week and average load of previous week, load at same hour and day of last year, day of the week (weekday or weekend) and weather forecast.

The Fig. 8 shows predicted model of load in red line and actual load in blue line. The load data is predicted according to the model given by ANN. Mean Absolute Percent Error (MAPE) is calculated and it is around $2.41 \%$, which is within permissible limit reported in literature.

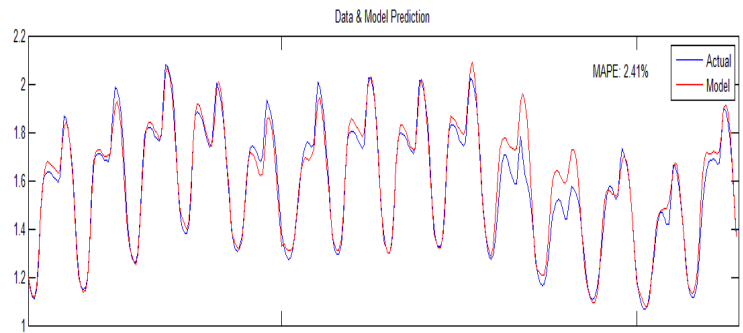

Fig. 8: ANN based Model and comparison with original load

\section{MICROGRID CASE STUDY}

Microgrid under study has primary system at $11 \mathrm{kV}$ the distribution near the load centers is $400 \mathrm{~V}$. There are three modules of PV generation of total $500 \mathrm{~kW}$ installed capacity. It has two wind turbines of $250 \mathrm{~kW}$ each. Two low head micro-hydro run of river turbines rated to $250 \mathrm{~kW}$. There are three diesel generators each of capacity $500 \mathrm{~kW}$ for assisting the renewables in meeting the load demand. Base thermal generator of 2.5 MW is installed that can bear full load of the island in case no other source is available. Microgrid under study has some residential load (1.81 MW) and commercial load (0.2 MW). Maximum peak of total load is around $2 \mathrm{MW}$ and base load is $1.3 \mathrm{MW}$. A dump load unit is also present to cater the excess of renewable energy.

There is battery storage unit which consist of lead-acid batteries with total capacity of 10800Ah. Battery charging and discharging is done through $\mathrm{DC} \sim \mathrm{AC}$ and AC $\sim D C$ converters at distribution level of $400 \mathrm{~V}$ (near load centres). Including the efficiencies and degradation factor, maximum current drawn from the batteries is limited to 700 amps at the distribution level of 400 volts. So, battery unit is limited to give $280 \mathrm{~kW}$ instantaneous power to the Microgrid. The SOC of battery bank is then calculated and updated accordingly in case of charging or discharging. Basic 


\begin{tabular}{|c|c|c|}
\hline \multicolumn{3}{|c|}{ Table 1: Renewable generation specifications in } \\
Microgrid under study \\
\hline $\begin{array}{c}\text { Renewable } \\
\text { Generation } \\
\text { Type }\end{array}$ & Parameters & Specification \\
\hline PV & & \\
System & Area & $5000\left(\mathrm{~m}^{2}\right)$ \\
\cline { 2 - 3 } & Efficiency of whole & $10 \%$ \\
\hline Wind & system & \\
\cline { 2 - 3 } Turbine & Cut installed Power & $500(\mathrm{~kW})$ \\
\cline { 2 - 3 } & Cut out wind speed & $2.5(\mathrm{~m} / \mathrm{s})$ \\
\cline { 2 - 3 } & Rated wind speed & $11(\mathrm{~m} / \mathrm{s})$ \\
\hline Micro- & Total Installed Power & $500(\mathrm{~m} / \mathrm{s})$ \\
Hydro & Rated Streamflow & $0.25\left(\mathrm{~m}^{3} / \mathrm{s}\right)$ \\
Power & Efficiency & $70 \%$ \\
Plant & Head & $141(\mathrm{~m})$ \\
\hline Battery & Total Capacity & $10800(\mathrm{Ah})$ \\
Bank Unit & Voltage & $400(\mathrm{~V})$ \\
& Charging/Discharging & $700(\mathrm{~A})$ \\
& Current & \\
\hline \multicolumn{2}{|c|}{} \\
\hline
\end{tabular}

parameters of components of Microgrid under study are listed in Table 1:

Generation costs and load data of a resort island used in a recent study [47-48] was taken as it is in this study for the purpose of comparison. Generation costs are listed in Table 2.

Table 2: Per unit cost of each type of generation

\begin{tabular}{|c|c|}
\multicolumn{2}{|c|}{ [47] } \\
\hline Power Source & Cost $(\$ / \mathrm{kWh})$ \\
\hline Micro-Hydro Turbine & 0.045 \\
\hline Wind & 0.078 \\
\hline PV & 0.078 \\
\hline Battery & 0.056 \\
\hline Thermal & 0.157 \\
\hline
\end{tabular}

Improvement in terms of intelligence and cost reduction has been achieved in this research work compared to previous work done.

\section{RESULTS AND DISCUSSION}

Simulation of the decentralized intelligent control and management of microgrid is tested for 24-hour load profile of the island. The load profile of island under study of island is shown in Fig. 9.

The profiles of hydel stream flow, solar irradiance, wind speed and are shown in Fig. 10, Fig. 11 and Fig. 12 respectively.

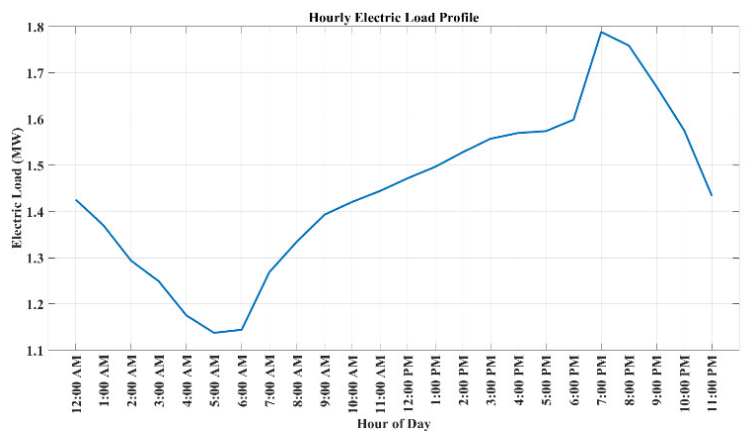

Fig. 9: Typical electrical load profile of a day

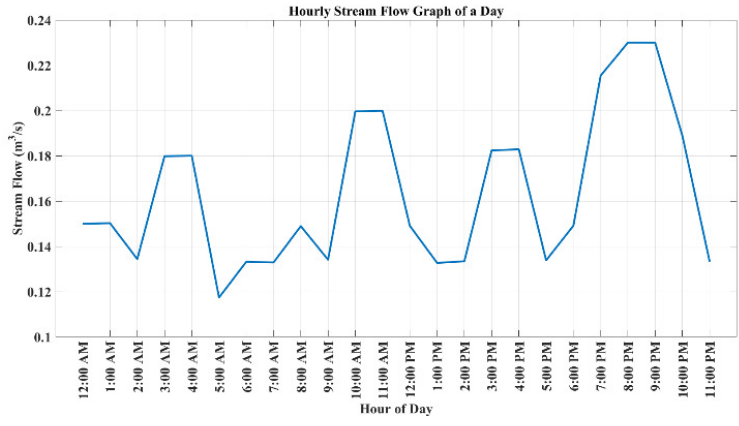

Fig. 10: Stream flow graph for micro-hydro plant

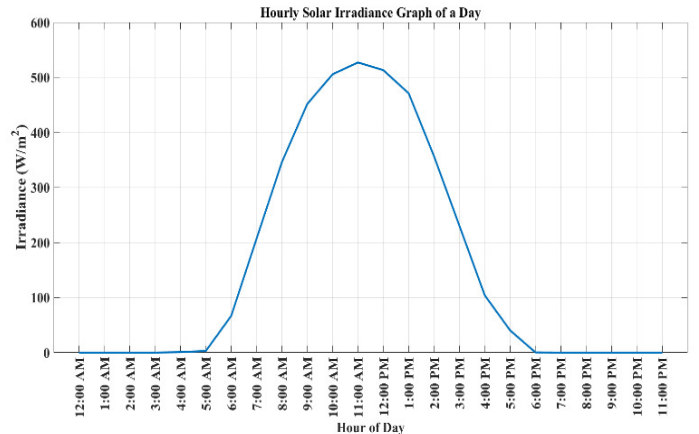

Fig. 11: Hourly solar irradiance graph of a day

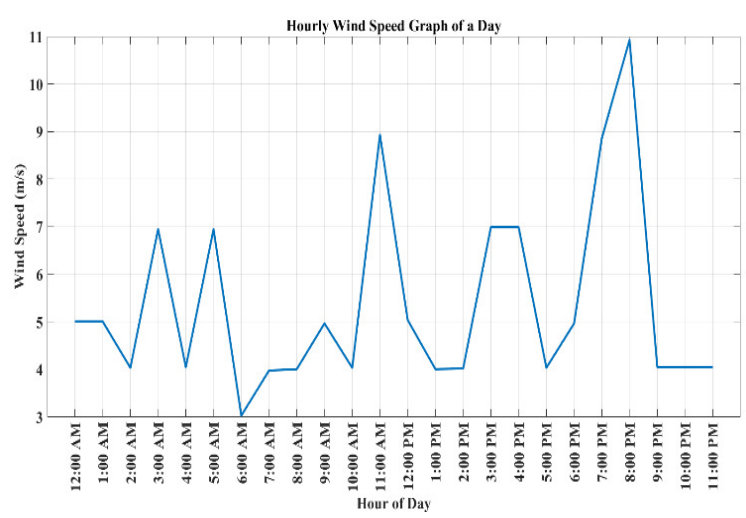

Fig. 12: Hourly wind speed graph 


\section{MATLAB Simulink ${ }^{\mathrm{TM}}$ ENVIRONMENT}

All the agents and the individual components are modelled as single subsystem in the microgrid using MATLAB Simulink environment. A simulation diagram is shown in Fig. 13.

\subsection{Simulation Output}

From the above given profiles of different sources and load, the modeled sources are provided with respective inputs and all type of generations took part to meet the load demand. All the generations are shown in single graph in Fig. 14. The difference between load demand and renewable sources is delta $\mathrm{P}$ (shown in dash-dot red line in graph). This difference must be compensated by the combination of batteries and thermal generation. A graph showing the battery power consumed and SOC throughout the 24 hours is shown in Fig. 15.

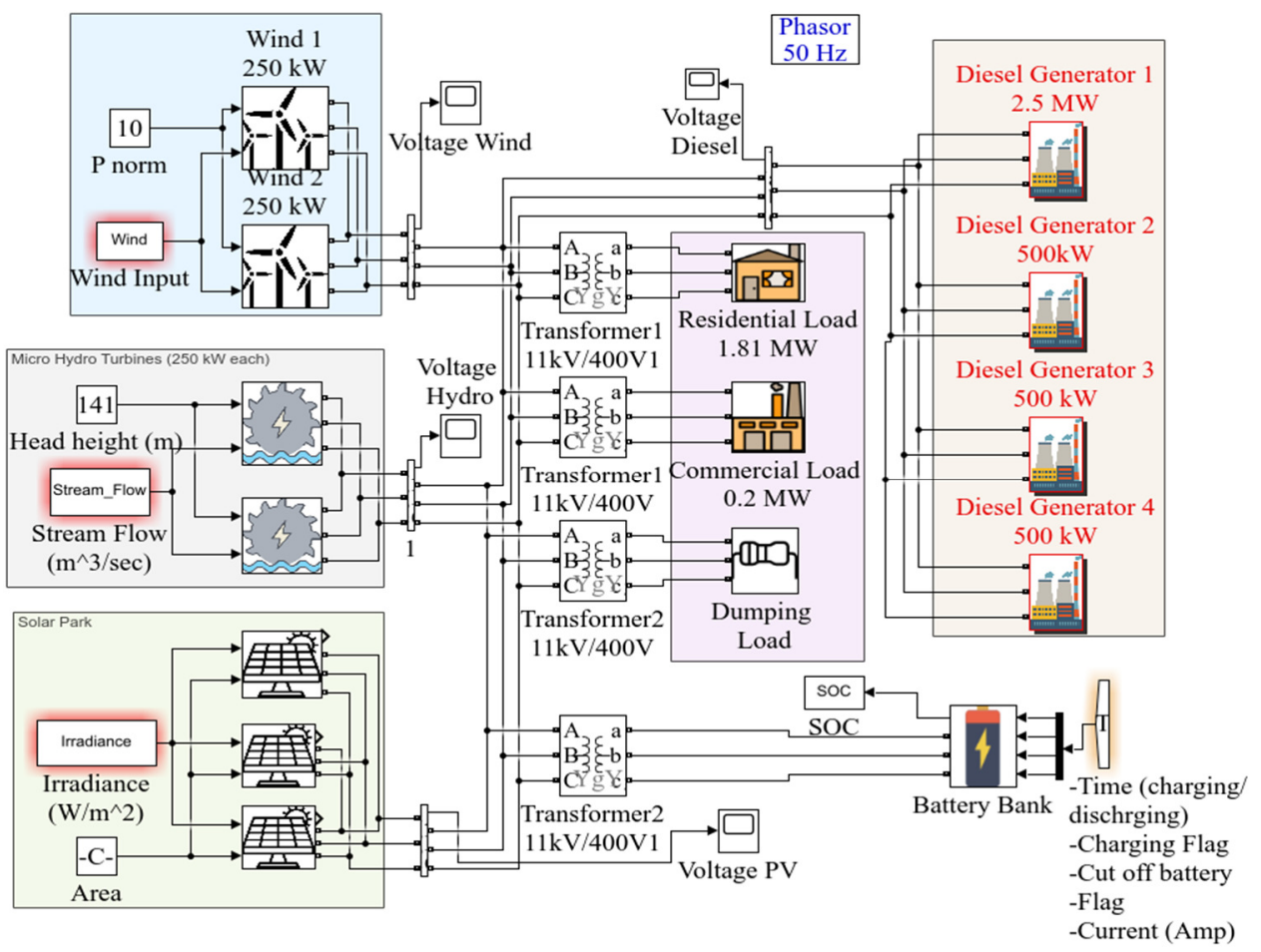

Fig. 13: Simulink model diagram of Microgrid

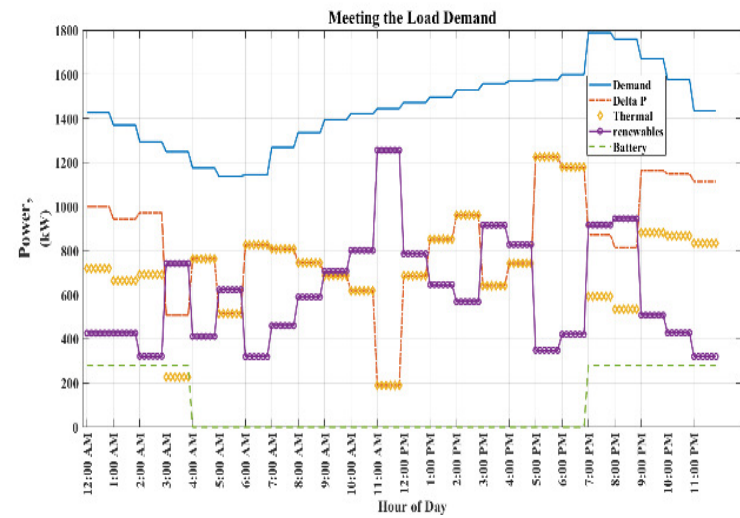

Fig. 14: Share of individual generation to meet the load demand

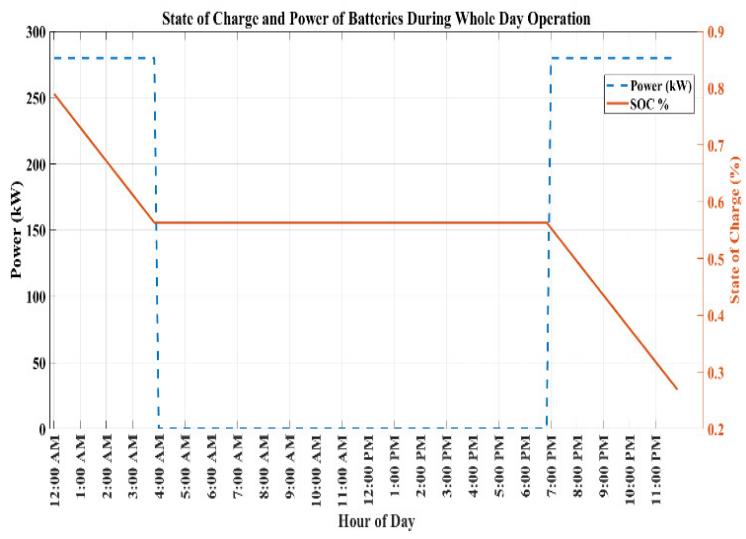

Fig. 15: Battery power and SOC throughout the day 


\section{COMPARISON WITH REPORTED LITERATURE}

Decentralized multi agent based intelligent control and management technique with ANN presented in this work is compared with the multi agent control and management without learning process previously reported in literature [48] under the same load profile conditions.

In Fig. 16(a), generation share by each generator is shown when learning based planning is not considered. The thermal share is $52 \%$ of total generation and battery share is $11 \%$ during whole day to meet the load demand.

With integration of ANN learning and planning in decentralized multi agent control and management system, the same situation (load demand) for whole day is tested and share of thermal generation is around 49\% (Fig. 16(b)). The second expensive component (other than RES) was batteries and share of batteries was also reduced to $7 \%$ from $11 \%$. Which helps to achieve a part of intended goal of this study, i.e. minimization of cost of operation. [47] and [48] concluded that reduction of battery usage plays role in optimization because of its dynamic nature of acting as load and source throughout day.

By comparison of both Fig. 16(a) and Fig. 16(b), it can be concluded that the technique presented in this work utilized the renewables more intelligently hence reducing the overall cost of operation by reducing the share of two most expensive sources i.e. thermal and batteries.

Similarly, the cost of each generation by both methods are given in Fig. 17. Fig. 17 shows $74 \%$ of total cost is coming from the thermal unit which are most expensive generation (Table 2). With intelligent technique of control and management of power flow this cost is reduced to $72 \%$ of total cost.

Cost comparison of case under study by both management techniques are shown in Fig. 18.

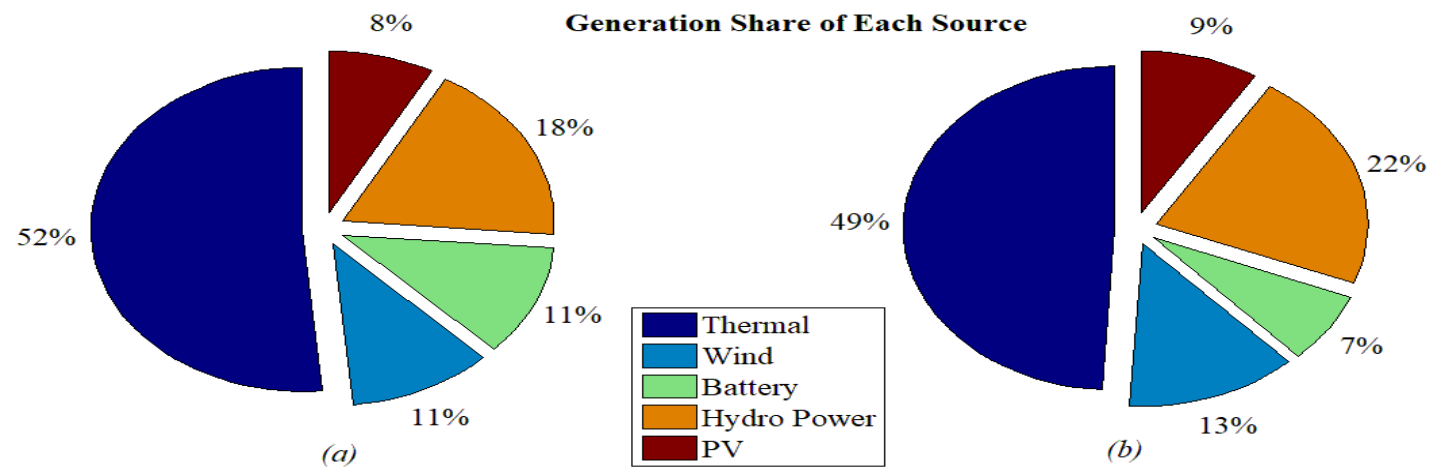

Fig. 16: Share of each generation (a) in [48] and (b) by developed technique
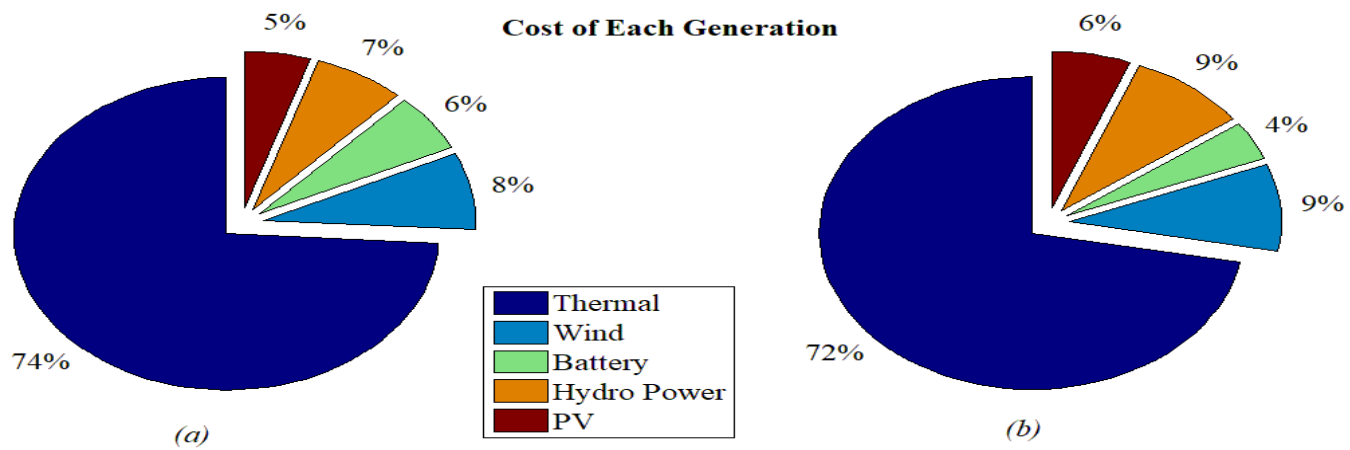

Fig. 17: Cost share of each generation in whole day $(a)$ in [48] (b) by developed technique 


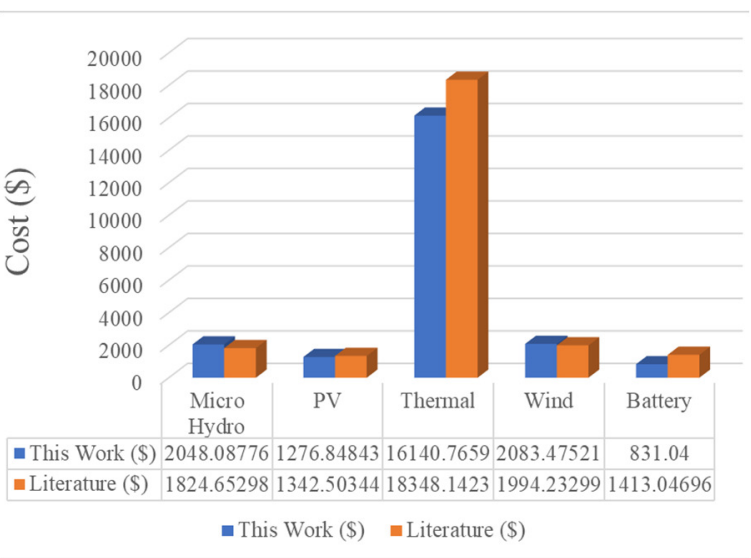

Fig. 18: Cost comparison bar graph

\subsection{Comparison and Performance Evaluation:}

The efficiency of the whole single network can be analysed by the level of power loss and share of thermal generation in whole system, as by the following equation:

$$
\eta_{\text {sys }}=\frac{\mathrm{P}_{\text {load }}}{\mathrm{P}_{\mathrm{RES}}+\mathrm{P}_{\text {thermal }}}
$$

Although this gives the idea of system behaviour but when intermittent natured sources are available in network, this can be misleading about the power flow under different situations with multiple control and management systems. Moreover, the source and load behaviour of storage units is not considered by using this method. These issues are identified in [49] and authors provided solution for comparison of different type of networks. A method of relative performance evaluation is suggested in [49] as follows:

$$
\begin{aligned}
& \alpha=\frac{P_{\text {load }}}{P_{\text {RES }}} \\
& \eta_{\text {sys }}=\frac{\alpha}{1+\left(\frac{P_{\text {thermal }}}{P_{\text {RES }}}\right)}
\end{aligned}
$$

For efficiency comparison of centralized controller with intelligent multi agent based decentralized controller of RES based Microgrid, we use this relative performance evaluation method. Final graphs of relative efficiencies are shown in Fig. 19. Fig. 19 shows that decentralized control and management system has higher efficiency most of the time. For further comparison, 2-norm of efficiencies is calculated, over the whole period. Analysis shows that the 2-norm of decentralized system is greater, representing the higher efficiency of the proposed system compared to centralized control. This shows the effectiveness of proposed approach in this work over the one in [48].

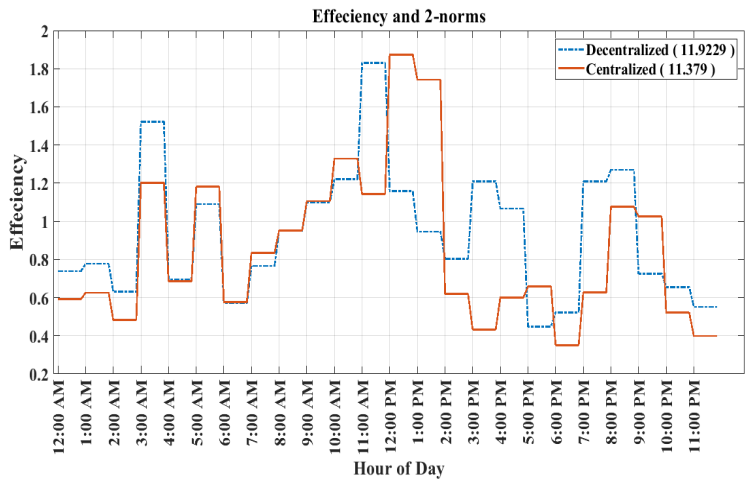

Fig. 19: Relative efficiencies of centralized and decentralized systems with 2-norms

\section{A LOCAL MICROGRID STUDY}

Another case study on data of a Microgrid different from the above is presented in this section to test the developed control and management technique. The algorithm developed was applied to a Microgrid data to show the general versatility and efficiency of the algorithm. Simulation results are shown in Fig. 20:

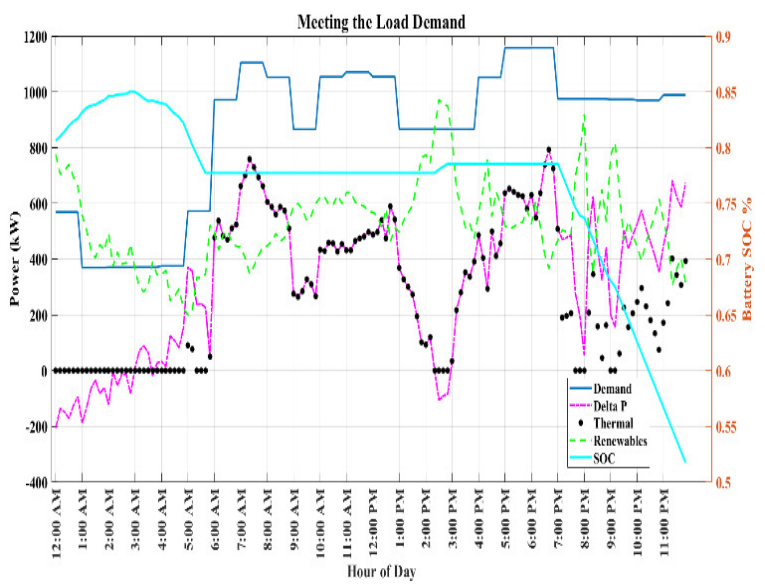

Fig. 20: A local Microgrid case study

As shown in Fig. 20, the renewable generation at 12am exceeds the load demand and delta $\mathrm{P}$ (difference between load and renewables) is negative and thermal generators are at cold standby mode. Batteries that were not fully charged are charged with this excess 
renewable power (Fig. 20). After the batteries are fully charged, there is still excess renewable power available which is consumed by dump load. Hence, agent and battery charging function is also functional and active. This excess renewable power continues and after $3 \mathrm{am}$ the load demand is higher than the renewables, batteries start to discharge to meet the load demand. During the day, batteries are at standby (inactive for discharging but hot standby for charging), unit 1 of thermal generation is turned on. The system observes another peak of renewables, higher than the load demand, later in day around 2:30pm and batteries again started to charge.

This case study covers all the functionalities of smart grid and proves the functionality and efficiency of the decentralized intelligent multi agent control and management system for integration of renewable energy sources in Microgrid.

\section{CONCLUSION:}

Timeline of evolution of power system towards Microgrid and further improvement in control strategies for better, efficient and reliable microgrid is presented. The solution to extensive communication burden and very high computations by single controller in centralized management and control approach, is proposed as decentralization of controllers of individual components in microgrid. Multi agent based decentralized intelligent control and management technique provides solution to the handling of multiple sources in microgrid with diversities in nature of individual component. Though agent itself is intelligent but for better response time and improved decision-making ability, ANN based learning and planning is introduced to achieve objective. Results when compared with previous work presented in literature have shown improvement in terms of minimizing the cost and thermal emissions and minimal interruption. Most costly thermal generations are set to cold standby by this control and management strategy which was in active state and not taking part in Microgrid operation. This not only reduced the cost and thermal generation but also provided better management of available renewables. The 2-norm analysis indicates the higher efficiency of decentralized system compared to centralized control.
The technique is tested under different situations (harsh and soft) to test the reliability of the control system.

This research can be extended in future with the further integration of other learning and prediction techniques at grid level as well as planning level of individual agents. The Microgrid environment with multi agent intelligence can be introduced in market environment to buy and sell the power to achieve best of interests for all stakeholders.

\section{REFERENCES:}

1. Ton D. T., Smith M. A., "The U.S. Department of Energy's Microgrid Initiative", The Electricity Journal, Vol. 25, No. 8, pp. 84-94, October, 2012.

2. Logenthiran T., Srinivasan D., Wong D., "Multiagent coordination for (DER) in MicroGrids", Proceedings of the International IEEE Conference on Sustainable Energy Technologies, pp. 77-82, Singapore, 24- 27 November 2008.

3. Mahmoud M. S., Azher Hussain S., and Abido M. A., "Modeling and control of microgrid: An overview", Journal of the Franklin Institute, Vol. 351, No. 5, pp. 2822-2859, 2014.

4. Nunna H. S. V. S.N., Doolla, S., "Multiagentbased distributed energy-resource management for intelligent microgrids", IEEE Transactions on Industrial Electronics, Vol. 60, No. 4, pp. 16781687, 2013.

5. Ackermann T., Andersson G., Söder L., "Distributed generation: a definition", Electric Power Systems Research, Vol. 57, No. 3, pp. 195204, April ,2001.

6. Hatziargyriou N., Asano H., Iravani R., Marnay, C., "Microgrids," IEEE Power and Energy Magazine, Vol. 5, No. 4, pp. 78-94, July 2007.

7. Nunna H. S. V. S.N, Saklani A. M., Sesetti A., Battula S., Doolla S., Srinivasan D., "Multi-agent based Demand Response management system for combined operation of smart microgrids," Sustainable Energy, Grids and Networks, Vol. 6, pp. 25-34, 2016.

8. McArthur S. D. J., Davidson E. M., Catterson V. M., Dimeas A. L., Hatziargyriou N. D., Ponci F., Funabashi T., "Multi-agent systems for power 
engineering applications - Part I: Concepts, approaches, and technical challenges", IEEE Transactions on Power Systems, Vol. 22, No. 4, pp. 1743-1752, 2007.

9. McArthur S. D. J., Davidson E. M., Catterson V. M., Dimeas A. L., Hatziargyriou N. D., Ponci F., Funabashi T., "Multi-agent systems for power engineering applications - Part II: Technologies, standards, and tools for building multi-agent systems", IEEE Transactions on Power Systems, Vol. 22, No. 4, pp. 1753-1759, 2007.

10. Khan A. R., Mahmood A., Safdar A., Khan Z. A., Khan N. A., "Load forecasting, dynamic pricing and DSM in smart grid: A review", Renewable and Sustainable Energy Reviews, Vol. 54, pp. 1311-1322, February 2016.

11. Zheng J., Xu C., Zhang Z., Li X., "Electric Load Forecasting in Smart Grids Using Long-ShortTerm-Memory based Recurrent Neural Network", Proceedings of the 51st Annual Conference on Information Sciences and Systems (CISS), pp. 1-6, Baltomore, U.S.A., 2017.

12. Afzaal A., Nazir M., "Optimizing Electricity Load and Cost for Demand Side Management in Smart Grid", Mehran University Research Journal of Engineering and Technology, Vol. 37, No. 4, pp. 633-644, 2018.

13. Nawaz, M. A., Raheem A., Shakoor R., Anwar Z., "Feasibility and Optimization of Standalone PVBiogas Hybrid Distributed Renewable System for Rural Electrification: A Case Study of a Cholistan Community”, Vol. 38, No. 2, pp. 453-462, 2019.

14. Dedinec A., Filiposka S., Dedinec A., Kocarev L., "Deep belief network based electricity load forecasting: An analysis of Macedonian case", Energy, Vol. 115, pp. 1688-1700, November, 2016.

15. Sun Q., Yang L., "Smart energy: From independence to interconnection-A review of AI technology applied in energy systems", CSEE Journal of Power and Energy Systems, pp. 1-15, 2019.

16. Panigrahi S., Karali Y., Behera S. H., "Time Series Forecasting using Evolutionary Neural Network", International Journal of Computer Applications, Vol. 75, No. 10, pp. 13-17, 2013.

17. Khwaja A. S., Zhang X., Anpalagan A., Venkatesh B., "Boosted neural networks for improved short-term electric load forecasting", Electric Power Systems Research, Vol. 143, pp. 431-437, 2017.

18. Lee K. Y., Cha Y. T., Park J. H., "Artificial neural network methodology for short term load forecasting", Proceedings of the NSF Workshop on Artificial Neural Network Methodology in Power System Engineering, pp. 109-113, Clemson N.C., 9-10 April 1990.

19. Lue C.-N., Wu H.-T., Vemori S.," "Neural Network Based Short Term Load Forecasting", IEEE Transactions on Power Systems, Vol. 8, No. 1, pp. 336-342, 1993.

20. Hernandez L., Baladron C., Aguiar J. M., Carro, B., Sanchez-Esguevillas A., Lloret J., Chinarro D., Gomez-Sanz J. J., Cook D., "A multi-agent system architecture for smart grid management and forecasting of energy demand in virtual power plants", IEEE Communications Magazine, Vol. 51, No. 1, pp. 106-113, January 2013.

21. Raza M. Q., Khosravi A., "A review on artificial intelligence based load demand forecasting techniques for smart grid and buildings", Renewable and Sustainable Energy Reviews, Vol. 50, pp. 1352-1372, 2015.

22. Hashem I. A. T., Chang V., Anuar N. B., Adewole K., Yaqoob I., Gani A., Ahmed E., Chiroma H., "The role of big data in smart city", International Journal of Information Management, Vol. 36, No. 5, pp. 748-758, October, 2016.

23. Feilmeier S., "Loads Management Based on Photovoltaic and Energy Storage System", PhD Thesis, University of Sibiu - Romania, 2015.

24. Sembroiz D., Careglio D., Ricciardi S., Fiore U., "Planning and Operational Energy Optimization Solutions for Smart Buildings", Vol. 476, pp. 439452, February 2019.

25. Olivares D. E., Mehrizi-Sani A., Etemadi A. H., Canizares C. A., Iravani R., Kazerani M., Hajimiragha A. H., Gomis-Bellmunt O., Saeedifard M., Palma-Behnke R., JimenezEstevez G. A., Hatziargyriou N. D., "Trends in Microgrid Control", IEEE Transactions on Smart Grid, Vol. 5, No. 4, pp. 1905-1919, July, 2014.

26. Wooldridge M., "Agent-Based Software Engineering in Software Engineering", IEE Proceedings, Vol. 144, No. 1, pp. 26-37, 1997.

27. Jackson P., "Introduction to expert systems" 
Addison-Wesley Longman Publishing Co., Inc., 1998.

28. Hayes-Roth F., Waterman D., Lenat D. B., "Building Expert Systems" Addison-Wesley, New York, 1983.

29. Jennings N., Mamdani E., Corera J., Laresgoiti I., Perriolat F., Sharek P., Varga L., "Using ARCHON to develop real-world DAI applications Part 1", IEEE Expert, Vol. 11, No. 6, pp. 64-70, 1996.

30. Russell S. Norvig P., "Artificial intelligence: $a$ modern approach", Upper Saddle River, Prentice Hall, New Jersey, 2016.

31. Guha R. V. Lenat D. B., "Enabling agents to work together", Communications of the ACM, Vol. 37, No. 7, pp. 126-142, July ,1994.

32. Malatestas P. B., Papadopoulos M.P., Stavrakakis G. S., "Modeling and identification of diesel-wind turbines systems for wind penetration assessment", IEEE Transactions on Power Systems, Vol. 8, No. 3, pp. 1091-1097, 1993.

33. Miao Z., Domijan A., Fan L., "Investigation of microgrids with both inverter interfaced and direct AC-connected distributed energy resources", IEEE Transactions on Power Delivery, Vol. 26, No. 3, pp. 1634-1642, 2011.

34. Habib M., Said S. A., El-Hadidy M., aAl-Zaharna I., "Optimization procedure of a hybrid photovoltaic wind energy system", Energy, Vol. 24, No. 11, pp. 919-929, November ,1999.

35. Duffie J. A., Beckman W. A., "Solar Engineering of Thermal Processes", Vol. 116. Wiley, U.S.A., 2003.

36. Markvart T., "Solar Electricity." Wiley, U.S.A, 2000.

37. Deshmukh M. K., Deshmukh S. S., "Modeling of hybrid renewable energy systems", Renewable and Sustainable Energy Reviews, Vol. 12, No. 1, pp. 235-249, 2008.

38. Chedid R., Akiki H., Rahman S., "A Decision Support Technique for the Design of Hybrid Solar-Wind Power Systems", IEEE Transactions on Energy Conversion, Vol. 13, No. 1, 1998.

39. Zhao B., Zhang X., Chen J., Wang C., Guo L., "Operation optimization of standalone microgrids considering lifetime characteristics of battery energy storage system", IEEE Transactions on Sustainable Energy, Vol. 4, No. 4, pp. 934-943,
2013.

40. Bosona T. G., Gebresenbet G., "Modeling hydropower plant system to improve its reservoir operation", International Journal of Water Resources and Environmental Engineering, Vol. 2, No. 4, pp. 87-94, 2010.

41. Acakpovi A., Hagan Ben E., Fifatin F. X., "Review of Hydropower Plant Models", International Journal of Computer Applications Vol. 108, No. 18, pp. 33-38, 2014.

42. Yang H., Lu L., Zhou W., "A novel optimization sizing model for hybrid solar-wind power generation system", Solar Energy, Vol. 81, No. 1, pp. 76-84, January, 2007.

43. Wu K., Zhou H., "A multi-agent-based energycoordination control system for grid-connected large-scale wind-photovoltaic energy storage power-generation units", Solar Energy, Vol. 107, pp. 245-259, 2014.

44. Guasch D., Silvestre S., "Dynamic battery model for photovoltaic applications", Progress in Photovoltaics: Research and Applications, Vol. 11, No. 3, pp. 193-206, May 2003.

45. Müller J. P., Pischel M., "InteRRaP: eine Architektur zur Modellierung flexibler Agenten.”, Verteilte Künstliche Intelligenz - Methoden und Anwendungen (Distributed Artificial Intelligence - Methods and Applications), pp. 45-54, 1993.

46. Amjady N., Keynia F., Zareipour H., "Short-Term Load Forecast of Microgrids by a New Bilevel Prediction Strategy", IEEE Transactions on Smart Grid, Vol. 1, No. 3, pp. 286-294, December 2010.

47. Basir Khan, M. R., Jidin R., Pasupuleti J., Shaaya S. A., "Optimal combination of solar, wind, micro-hydro and diesel systems based on actual seasonal load profiles for a resort island in the South China Sea", Energy, Vol. 82, pp. 80-97, 2015.

48. Basir Khan M. R., Jidin R., Pasupuleti,J., "Multiagent based distributed control architecture for microgrid energy management and optimization", Energy Conversion and Management, Vol. 112, pp. 288-307, March ,2016.

49. Bruni G., Cordiner S., Mulone V., "Domestic distributed power generation: Effect of sizing and energy management strategy on the environmental efficiency of a photovoltaic- 
battery-fuel cell system", Energy, Vol. 77, pp. 133-143, 2014. 